\title{
Correction to: Survey of coastal inland pollution sources and their influence on seawater quality in Doam bay, Korea
}

\author{
Jinsoo Suh • Seyeon Shin • Hyung-Yeel Kahng • \\ Samyoung Ahn $\mathbb{D} \cdot$ Young-Sun Lee • Jae-Sung Jung
}

Published online: 31 October 2018

C) Springer Nature Switzerland AG 2018

\section{Correction to: Environ Monit Assess (October 2018) 190:605 \\ https://doi.org/10.1007/s10661-018-6982-y}

The original version of this article unfortunately contained an error in the affiliation section.

Young-Sun Lee the fifth author should only be affiliated to Department of Biology, Research Institute for Sanitation and Environment of Coastal Areas, Sunchon National University, 57922 Suncheon, Republic of Korea

The corrected affiliation is shown below.

J. Suh $\cdot$ S. Shin $\cdot$ H.-Y. Kahng $\cdot$ S. Ahn $(\bowtie)$

Department of Environmental Education, Research Institute for Sanitation and Environment of Coastal Areas, Sunchon National University, 57922 Suncheon, Republic of Korea

e-mail:sahn@sunchon.ac.kr

Y.-S. Lee · J.-S. Jung

Department of Biology, Research Institute for Sanitation and Environment of Coastal Areas, Sunchon National University, 57922 Suncheon, Republic of Korea 